\title{
CERTAIN DEVELOPMENTAL RELATIONS AND FIBER CONNECTIONS OF THE TRIANGULAR GYRUS IN PRIMATES
}

\author{
ISABEL LOCKARD ${ }^{1}$ \\ Department of Anatomy, University of Michigan, Ann Arbor
}

TWENTY-FIVE FIGURES

INTRODUCTION

The foundation for most of our knowledge of the cortical aspects of speech was laid by the work on aphasia of various early observers such as Broca (1861a, 1861b), Jackson (Head, '15), Wernicke (1874), and Marie ('06a, '06b, '06c), and more recently Goldstein ('26), Head ('26), Weisenberg and McBride ('35) and Nielsen ('47). Apart from their studies little attention has been given to the neurological patterns involved either in normal speech or in speech disorders.

It is the purpose of this paper to present certain anatomical observations which are related to this subject. Fundamental to an understanding of either normal or pathological speech is a knowledge of the development of the so-called speech centers of the brain with their relations to the rest of the developing cortex and, most especially, of their fiber connections.

The results presented in this paper, although not complete, provide a basis for further research on the speech centers. It is planned to continue this line of investigation as suitable human material becomes available.

'A dissertation submitted in partial fulfillment of the requirements for the degree of Doctor of Philosophy in the Department of Anatomy, University of Michigan. 
I wish to thank the Horace H. Rackham School of Graduate Studies of the University of Michigan for the generous grant which aided in this study. Most of all I am indebted to Professor Elizabeth C. Crosby, under whose careful direction this paper was planned and executed.

\section{I.ITERATURF}

Four books were used extensively in the preparation of this paper. They are "Contribution to the Surface Anatomy of the Cerebral Hemispheres with a Chapter upon Craniocerebral Topography by V. Horsley' by Cunningham (1892), "Das Menschenhirn"' and "Das Affenhirn" by Retzius (1896, '06), and "The Comparative Anatomy of the Nervous System of Vertebrates Including Man" by Ariëns Kappers, Huber and Crosby ('36). Pertinent details obtained from various papers in the literature are discussed in the text.

\section{MATERIAL AND METHODS}

In the study of the ontogenetic development of the neopallium, the brains of 19 human fetuses, of one newborn and of one two-year-old child were used. This material was made available at the University of Pittsburgh through the courtesy of Dr. Davenport Hooker. The ages of the fetuses were estimated according to the Boyd scale ('41) for the crown-rump length (table 1). A margin of error was recognized as caused by variation in size of fetuses of a given age, and probably by swelling as well, in that the material was fixed in $10 \%$ formalin. An example of this unavoidable inaccuracy is shown in fetuses F17 and F18 (figs. 8 and 10) the ages of which were estimated at 27 and $29 \frac{1}{2}$ weeks, respectively. Fetus F17 had the better developed brain and perhaps was the older fetus.

The phylogenetic development of the triangular gyrus was studied from the brains of 11 monkeys ranging from Cercopithecus to Papio. Several of these brains were gifts of Dr. Fred Mettler (Department of Neurology, College of 
Physicians and Surgeons, Columbia University) to the Laboratory of Comparative Neurology, Department of Anatomy, University of Michigan. The material, both human and monkey, was supplemented extensively by the many fine illustrations in Retzius' atlases (1896, '06).

For the study of the fiber connections, the brain of Macaca mulatta was used. Two series, cut transversely (A at $20 \mu$ and $B$ at $30 \mu$ ) and stained according to the Weil method, were available for study from the Huber Neurological Collection.

A blotter reconstruction of the cerebrum was made from the macaque series $B$, for use in the study of fiber connections. Sections were traced at a magnification of $4.3 \times$. Twentytwo out of every 100 sections were used so that the complete reconstruction approximated 4.3 times the length of the original brain. The model (figs. 24 and 25) was used to relate gyri and sulci as seen in cross section to the surface of the brain so that the fiber bundles under consideration could be located accurately with respect to their cortical relation.

ONTOGENETIC DEVELOPMENT OF CERTAIN NEOPALLIAL REGIONS

\section{Lateral wall and insula}

Early in development the cerebrum is somewhat beanshaped with the frontal pole most anterior and the temporal pole most posterior. The occipital pole is not evident as a protuberance (see His-Ziegler model of brain of $13.6 \mathrm{~mm}$ human embryo). As the brain enlarges, the pallium envelops the basal ganglia and the thalamus. This overlapping of the more centrally-placed structures occurs in all directions, the posterior part of the pallium showing the most conspicuous change in position. The temporal lobe extends downward and anteriorly, bringing the occipital pole into view. By approximately 16 weeks (F5) the temporal lobe has assumed a position approaching that at term and in fetuses a few weeks older (F11 and F15) it has completed its shift forward. During this process, the occipital lobe gradually descends into a position comparable to that which it occupies at birth. It 
is during this early period that the brain enlarges most rapidly. As the fissural pattern appears, the expansion is retarded, this being a period of differentiation (compare fig's. 1-6 with figs. 6-12).

As the temporal lobe shifts downward and anteriorly, it forms the Sylvian fossa (Jordan and Kindred, '32). The floor of this fossa is the primordium of the insula. The cortex in this region (nearest corpus striatum) is the first to thicken and differentiate (Streeter, '12; Kodama, '26). By 9 or $9 \frac{1}{2}$ weeks fascicles can be traced from insular cortex into the internal capsule. Thus the insula, anchored firmly to the underlying structures, retains its position as the temporal

TABLE 1

Data concerning fetuses used in study

\begin{tabular}{|c|c|c|}
\hline NO. OF FETUS ${ }^{1}$ & $\begin{array}{l}\text { C--R LFNGTH } \\
\text { IN MM }\end{array}$ & $\begin{array}{l}\text { APPROXIMATE AGF } \\
\text { IN WEIKS ACE. TO } \\
\text { BOYD SCALE }\end{array}$ \\
\hline F1 & 54 & $10 \frac{t}{2}$ \\
\hline $\mathrm{F} 2$ & 65 & 11 \\
\hline $\mathrm{F3}$ & 109 & $14 \frac{2}{2}$ \\
\hline F4 & 112 & $14 \frac{1}{2}$ \\
\hline F5 & 119 & $15 \frac{1}{2}$ \\
\hline E6 6 & 123 & $15 \frac{1}{12}$ \\
\hline F7 & 131 & 16 \\
\hline F8 & 134 & $16 \frac{1}{2}$ \\
\hline F9 & 136 & $16 \frac{1}{2}$ \\
\hline F10 & 152 & 18 \\
\hline F11 & 162 & 19 \\
\hline F12 & 167 & 19 \\
\hline F13 & 182 & $20 \frac{1}{2}$ \\
\hline F14 & 197 & 22 \\
\hline F15 & 210 & 23 \\
\hline F16 & 220 & 24 \\
\hline F17 & 246 & 27 \\
\hline F18 & 268 & $29 \frac{1}{2}$ \\
\hline F19 & 280 & 313 \\
\hline F20 & & 40 \\
\hline
\end{tabular}

1 The fetuses are numbered in order aceording to their estimated ages and these numbers are used throughout the text and on the figures. For convenience and completeness the brain (F20) of the baby at term is included in table 1. 
lobe pivots around it and, in the course of further development, becomes buried under the opercula.

The inferior limiting sulcus of the insula appears at about 15 weeks. The posterior part of the sulcus develops first (F3, F6). Soon thereafter the superior limiting sulcus is evident (F6). These two sulei join secondarily to form a C-shaped crease, the circular sulcus, which outlines the insula (fig. 2).

As the opercula begin to overlap the insula, the Sylvian fossa assumes a triangular shape (19 weeks, fig. 5). In the frontal operculum a fairly sharp angle is formed at the place where an anterior ramus of the lateral (Sylvian) fissure is seen in older fetuses. At about this time, or a little later, the insula begins to enlarge and the bulge which appears in its anterior portion (fig. 5) makes it possible to distinguish an anterior from a lateral surface. Concurrently the cortex anterior to the insula is enlarging and the anterior bounding ramus of the insula appears (fig. 6). As the opercula approach each other, the lateral surface of the insula exhibits a superior aspect under the parietal and frontal lobes and an inferior aspect under the temporal lobe.

In the material studied the central sulcus, which separates the long from the short gyri of the insula, appears at about 22 to 24 weeks (fig. 7 ). In Cunningham's series it was present toward the end of the 5th month, and according to Connolly ('40) it occurs at 25 or 26 weeks. In fetuses F17 and F18 the central sulcus of the insula is present only on the inferior aspect of the lateral surface, suggesting that the lower part of the sulcus develops first. At this stage, the central sulcus of the insula is in line with the fissure of Rolando (fig. 7; Eberstaller, 1887; Cunningham, 1891 and 1892), although this relationship is not evident in the adult. According to Cunningham (1891) the precentral sulcus of the insula appears shortly after the central sulcus and bears the same relationship to the precentral sulcus of the frontal lobe. The postcentral sulcus does not appear before the middle of the 6th month or later (Cunningham, 1892). In the material studied there was no indication of insular sulci other than the central 
in fetuses younger than $31 \frac{1}{2}$ weeks. In the fetus of that age (F19), as in the brain at term, all the insular sulci are present.

The lateral fissure closes in sections posteroanteriorly. At 22 weeks the posterior ascending ramus (fig. 13) and by $31 \frac{1}{2}$ weeks the portion between this ramus and a point underlying the central or precentral sulcus of the hemisphere is closed. This condition persists until after birth (fig. 12), the closure of the last and most anterior section of the fissure being effected by the postnatal development of the frontal and temporal association areas including their opercular portions. At two years of age the lateral fissure is completely closed.

\section{Precentral and postcentral gyri}

The pre- and postcentral gyri can be recognized first when their delimiting sulci appear. In the material studied the central and postcentral sulci are present at 22 weeks (F14). An earlier stage in the development of the central sulcus at the time it has two parts (described by Cunningham, 1892) is demonstrable in the 23 -week fetus (fig. 6 ) in which the postcentral and the superior and inferior precentral sulci are also present. According to Streeter ('12) the pre- and postcentral sulci appear soon after the central. The material studied and that depicted by Retzius (1896) support this view.

The two parts of the central sulcus of Rolando lengthen and join secondarily to form one shallow sulcus which, by 24 weeks (fig. 7), arches anteriorly and downward over the lateral surface of the hemisphere. The central sulcus continues to lengthen and by about 28 weeks the upper portion has buckled, thus forming the superior genu with its convexity directed anteriorly and the inferior genu with its convexity directed posteriorly. The lower part of the sulcus has remained comparatively straight except for a backward bending of the inferior tip, occasionally seen in fetuses of this age. Concurrent with this development in the contour of the sulcus is its extension onto the medial surface of the hemisphere (F17 and F19, fig. 11). Cunningham (1892) did 
not observe this medial extension until the beginning of the 10th month. By term (fig. 12) the contour of the central sulcus corresponds fairly well with that found in the adult brain.

There is a progression in development of the walls of the sulcus as well as of the surface contour. As the genua of the central sulcus develop, corresponding ridges, perpendicular to the surface of the brain, appear on the sulcal walls. The vertical ridges, however, are not dependent on the surface buckling of the sulcus, for they may appear before the genua are evident on the surface (F19). These ridges are more pronounced at term than in younger fetuses. On the anterior wall of the sulcus there are slight protusions which cause the sulcus to slant downward and somewhat posteriorly. At two years of age these protusions are so exaggerated that the walls of the sulcus are markedly irregular and its slant has correspondingly increased. The depth of the central sulcus (about $18 \mathrm{~mm}$ at the center) is approximately double that at term.

\section{Triangular gyrus}

For many years Broca's area (the triangular gyrus, together with the opercular and possibly the orbital portions of the inferior frontal gryus) was regarded as the cortical center for speech. Broca (1861a) was the first to report the disorder known as motor aphasia. Although in his patient the extent of brain damage was large, he attributed the loss of speech to destruction of the cortex in the region which bears his name. Later observers questioned the justification of this concept. Marie ('06a, '06b, '06c) and Marie and Foix ('17) believed that the inferior frontal gyrus did not play an essential role in the function of language, but that the important language center is in the posterior part of the superior temporal gyrus (Wernicke's area). Following their work and that of Head ('26) there arose the belief that speech is made possible by the integrative processes of various cortical areas. Localized areas, lesions of which produce aphasia, are currently regarded as nodal points in the fiber systems 
associated with speech. Such a nodal point is the left triangular gyrus in right-handed people.

The region that will develop into the triangular gyrus and the opercular portion of the inferior frontal gyrus can first be recognized as such when a horizontally-placed sulcus makes its appearance. This sulcus, extending forward from the superior limiting sulcus of the insula at its junction with the anterior bounding ramus, appears during the 6th month (fig. 6). It resembles the anterior horizontal ramus of the lateral fissure and, according to Cunningham (1892), was regarded as such by Broca. Cunningham himself (1892) believed that the wedge-shaped pars triangularis grows into the original single sulcus, thus producing both the anterior ascending and anterior horizontal rami. The relationship of the parts of this sulcal complex at various stages of development he described as resembling the letters $I, Y, V$, and $U$. In Kollmann's well-known illustration of a fetal brain at the end of the 7th month ('07, see his figure 621) a single horizontally-placed ramus is labelled the anterior ascending: ramus. With this interpretation our material agrees.

To differentiate the anterior ascending from the anterior horizontal ramus of the lateral fissure during their early development, two features characteristic of these sulci were used as criteria. At the age when both the anterior ascending and the anterior horizontal rami are present and readily distinguishable, the anterior ascending ramus is frequently found to bifurcate. The anterior horizontal ramus, however, is rarely forked, even at term. A second feature useful in the identification of the two anterior rami is the fact that the inferior frontal sulcus arches over the upper part of the anterior ascending ramus and may swing down into the triangular gyrus between the two anterior rami (fig. 8). Although the inferior frontal sulcus is occasionally discontinuous, its relationship to the anterior ascending ramus is, for the most part, constant. Usually the inferior frontal sulcus has no such relation to the anterior horizontal ramus, although occasionally it approaches this ramus. These two 
criteria (the bifurcation of the anterior ascending but not of the anterior horizontal ramus, and the relation of the inferior frontal sulcus to the anterior ascending but usually not to the anterior horizontal ramus) make it possible to establish the identity of the anterior rami in many cases, even though the sulci are not in their adult positions (fig. 14), or in case only one ramus is present (fig. 15). On the basis of these criteria it is possible to identify one or both of these rami by their positions and relations, before the anterior ascending ramus has bifureated or the inferior frontal sulcus is well-defined (fig. 13).

In the course of development, the anterior ascending ramus, originally horizontally-placed, shifts into an upright position. This change occurs gradually and, in the hemispheres studied and in Retzius' illustrations (1896), many intermediate stages are evident. Some of these early stages, before the horizontal ramus has appeared, are shown in figures 6,13 , and 15 . As the insula enlarges, its anterior portion displaces the Sylvian tip of the anterior ascending ramus downward and anteriorly. Growth of the frontal cortex must also play a part in determining the position of the sulcus. In many brains at about the end of the 7 th or beginning of the 8th month the anterior ascending ramus is bifurcated, although not uncommonly this sulcus is unforked in older fetuses and also in adult brains.

Usually the anterior horizontal ramus does not appear until the anterior ascending ramus has reached an angle of approximately $45^{\circ}$ with a plane running parallel to the base of the brain, although the ascending ramus may still be quite short. In some cases the anterior ascending ramus is bifurcated before the anterior horizontal ramus is first evident, and in others it is not bifurcated even though the anterior horizontal ramus has appeared (cf. figs. 7 and 15, anterior ascending ramus not labelled in fig. 7). When the anterior horizontal ramus appears, it slants downward or downward and anteriorly (fig. 14). Then, in the course of development, it swings upward into a horizontal or slightly 
ascending position (figs. $14,7,12$ ), the angle formed by the two rami remaining relatively constant.

Like the anterior ascending, the anterior horizontal ramus varies as to time of appearance and rate of development. In the material studied, it was absent on both sides in the 23-week fetus (fig. 6) but clearly evident on both sides in the 24-week fetus (fig. 7). In the Retzius material (1896), the anterior horizontal ramus was prominent in some brains as early as the 7 th month but in others it was no more than an indentation of the surface at 9 months.

The anterior rami of the two sides do not necessarily develop concurrently. Thus, in fetus F18 (291 weeks) the two anterior rami are present and approximately the same length on the right side, the anterior ascending ramus forming an angle of $44^{\circ}$ with a plane parallel to the base of the brain. On the left side, only one horizontally-placed ramus is present. Whether there is correlation between the presence of such unilaterally better developed anterior rami and dominance of the corresponding hemisphere was not determined.

In summarizing the development of the triangular gyrus it should be kept in mind that the relations are more nearly constant than is the time at which various changes take place. The triangular gyrus first becomes evident during the 6th month when the horizontally-placed anterior ascending ramus of the lateral fissure appears. At this time the primordium of the triangular gyrus lies below the anterior ascending ramus and in front of the insula. There is as yet no anterior horizontal ramus. As the insula enlarges and extends farther forward, the triangular gyrus is displaced to a position anterior to and above it. About midway in the course of this change in position, the anterior horizontal ramus appears. first being nearly vertical, then shifting with the triangular gyrus to a horizontal position. By term, the anterior ascending ramus has reached a vertical or nearly vertical position and the anterior horizontal ramus, a horizontal position.

The anterior ascending ramus frequently bifurcates at about the time the anterior horizontal appears. Cunningham 
(1892) interpreted the branches of the anterior ascending ramus as an early stage of the $\mathrm{Y}$ formation. Later, the two true anterior rami form a $Y, V$, or U. Such a relationship in the later stages represents the proportionate development of the fronto-parietal and orbital opercula on the one hand to that of the triangular gyrus on the other. These formations probably indicate individual variations and play no outstanding part in the development of the triangular gyrus.

\section{Auditory area}

The superior temporal sulcus develops by the fusion of two (or occasionally three) separate segments. At 23 weeks a posterior segment is present (fig. 6). By 24 weeks an anterior portion, underlying the postcentral gyrus, has appeared. By 28 weeks the anterior and posterior segments have joined and the superior temporal gyrus is demarcated (figs. $8,10)$.

At about the same period as the fusion of the parts of the superior temporal sulcus, a faint sulcus separates the primordium of the anterior from that of the posterior Heschl's convolution (fig. 10). Concurrently with the forward extension of the superior temporal sulcus, an anterior Heschl's convolution appears as a ridge on the upper surface of the superior temporal gyrus, although the region of the future posterior Heschl's convolution remains flat (fig. 8). The left side apparently precedes the right in development. Occasionally it is difficult to determine whether the ridge is the anterior or the posterior convolution of Heschl. At term, the anterior convolution lies behind the postcentral sulcus. The first ridge to appear underlies the postcentral sulcus or the postcentral gyrus, so it is probably the anterior convolution of Heschl. In the brain at term (fig. 12) two ridges, representing the anterior and posterior convolutions, are present.

There are certain differences between Heschl's convolutions at term and in the adult. At term the middle sulcus 
is visible for about $3 \mathrm{~mm}$ on the exposed surface of the superior temporal gyrus. In the adult this sulcus does not reach the surface of the lateral fissure. The sulcus forming the posterior boundary of the posterior convolution is shorter, in proportion to the middle sulcus, than it is in the adult. At term it also reaches the surface of the lateral fissure but not in the adult. A short convolution which lies posterolateral to the posterior Heschl's convolution is entirely visible on the surface at birth, but is hidden within the lateral fissure in the adult brain. At term Heschl's convolutions make up almost the entire upper surface of the superior temporal gyrus within the lateral fissure; in the adult there is a great increase in the opercular cortex behind and to a lesser extent in front of them. The differences between the auditory region at term and in the adult indicate changes in the association areas rather than in the projection area itself. The auditory association area, located in the superior temporal gyrus, continues to develop after birth and closes Heschl's convolutions, their sulci and the little convolution completely within the lateral fissure. Postnatal development of the auditory association area may also account for the increase in the opercularized cortex posterior and anterior to Heschl's convolution. During their development, Heschl's convolutions maintain a fairly constant position in relation to the insula, the surface of the lateral fissure and the postcentral gyrus. The auditory area develops late, therefore an arrest in development at or near term might still interfere with hearing. No morphological changes were noted which could be related to the development of a localization pattern such as that described by Woolsey and Walzl ('42).

\section{Visual area}

Before the cortex has begun to differentiate, the wall of the hemisphere is thin. The region overlying corpus striatum is the first cortical area to thicken and differentiate. From there growth of the wall gradually extends over the whole 
pallium (Streeter, '12). At 11 weeks (F2) the medial wall of the hemisphere is thin and smooth. By $14 \frac{1}{2}$ weeks (fig. 1), it has expanded without thickening appreciably and has become folded, forming bulges and intervening, radiallyarranged sulci on the medial surface. According to Kollmann (1898) this folding of the thin medial wall may occur as early as the 8 th week but reaches its maximum development during the third or 4 th month. With the development of corpus callosum and the consequent thickening of the medial wall, all or all but one or two of these sulci are obliterated

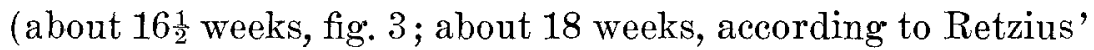
illustrations, 1896). Kollmann (1898) also noted that most of these sulci are transitory and that they disappear with the development of corpus callosum. Some observers have regarded these transitory sulci as artefacts produced by fixation (Mall, '03, Hochstetter-quoted by Symington, '01), however, evidence to the contrary lies in the fact that in malformed brains in which corpus callosum has failed to develop these sulci are not transitory but remain as permanent sulci of the medial wall (Ariëns Kappers, Huber and Crosby, '36). In normal brains, the two posterior sulci of this group may remain as primitive parieto-occipital and calcarine fissures, as in fetus F9 (fig. 3). Kollmann (1898) also stated that certain of the radially-arranged sulci may persist and that they coincide with the developing parietooccipital and calcarine fissures. In some hemispheres, however, these primitive sulci also are transitory, and the medial wall is left smooth (F8). In other hemispheres the parietooccipital fissure remains and the calcarine disappears (fig. 4) and in still others, the converse is true. Many examples of these variations are to be found in the material used for this study and in that illustrated by Retzius (1896).

In those hemispheres in which the early calcarine or parieto-occipital fissure, or both, are obliterated, the permanent fissures may not appear until much later. Among the hemispheres illustrated by Retzius (1896) there were specimens as 
old as 6 months in which there was no more than a suggestion of one (the other being present) or both of these fissures. If the early calcarine has disappeared, the permanent calcarine fissure develops in two parts - as a dimple on the medial occipital wall (F14) and as a notch on the posterior wall of the parieto-occipital fissure near its lower border (fig. 4). The dimple on the medial occipital wall elongates anteroposteriorly and becomes the posterior limb of the fissure. The notch on the wall of the parieto-occipital fissure extends backward to join that portion which has arisen independently. If the two early fissures have been retained, they may or may not join anteriorly ; frequently there is a marked depres sion or hollow in the region where they come together (fig. 3).

During the course of their development these fissures retain their original positions. However, if either the parieto-occipital or the calcarine fissure (or both) has developed secondarily and is therefore shallow, it deepens as the adjoining pallium increases in thickness. If both the early fissures have been retained, the characteristic depression at the point where they meet is obliterated by growth of the pallium in this region. Concurrently with this filling-in process, there is an extension of the fissural complex downward and anteriorly in line with the parieto-occipital fissure. This extension resembles the anterior limb of the calcarine fissure but in those hemispheres in which the parieto-occipital fissure is deeper than the calcarine, the floor of the extension is continuous with that of the former rather than that of the latter. In those hemispheres in which the floors of the two fissures are of approximately the same depth, a slight bulge in the floor separates the calcarine from the rest of the sulcal complex.

A later stage is evident in the fetus F18 in which the calcarine fissure, more shallow than the parieto-occipital, extends into the depth of the parieto-occipital, lying as a sulcus along its posterior wall. In fetus F17 the superior lip of the calcarine fissure has increased and turns downward into the parieto-occipital fissure where it ends. In this fetus, 
as in fetuses F19 (fig. 11) and F20, the anterior growth of the calcarine fissure has thus cut off the parieto-occipital fissure so that the extension becomes continuous with the calcarine fissure, forming its anterior limb, rather than the remaining a part of the parieto-occipital fissure. In brains of older fetuses, such as that of fetus F18, in which the parietooccipital fissure is deeper than the calcarine it is likely that the early parieto-occipital fissure was retained but that the primitive calcarine fissure was lost and later replaced.

The entire extension or anterior limb of the calcarinc fissure is visible on the medial surface (that is, not hidden by the cerebellum) from the time of its appearance until term. At two years of age an intermediate stage is reached. In the adult, the anterior limb of the calcarine fissure is usually concealed by the cerebellum.

During the 7th month, although sometimes as early as the 6th or as late as the 9th month according to Retzius' illustrations (1896), the posterior tip of the calcarine fissure widens (fig. 9). That part of the cortex which forms the floor of the fissure in this area enlarges, fills in the space between the two ealcarine lips, and thus forms the bifurcation so common to this fissure (fig. 11). It is this portion of the visual cortex - between the two arms of the bifurcation which receives impulses set up in the macular portion of the retina. This division of the calcarine fissure, present usually during the 7 th month in man, develops with the differentiation of the fovea centralis which "begins to form after the 6th month and is present in fetuses of $7 \frac{1}{2}$ or 8 months'" (Streeter, '12, p. 243).

During the last two months of intrauterine life, the calcarine fissure lengthens. If the fissure does not bifurcate, or if the arms of the bifurcation are short, the calcarine fissure tends to be longer than it does if the arms are long. At about term the tip of the calcarine fissure extends beyond the occipital pole onto the lateral surface of the brain for a variable distance. 


\section{Supramarginal and angular gyri}

Lesions of the supramarginal gyrus, which usually impinge on the temporal isthmus and therefore interfere with associations of the temporal lobe, may produce an amnesic aphasia (Nielsen, '47). In such types of aphasia there is difficulty in naming objects and frequently grave interference with the whole significance of language. The angular gyrus, bordering the visual psychic area, is regarded as a visual correlation center and a lesion in that area produces a sensory aphasia involving visual engrams. According to Nielsen ('47, p. 248), the angular gyrus is "the area of revisualization of the written word." Like the triangular gyrus, the supramarginal and angular gyri represent nodal points in the system of association fibers. Lesions involving these gyri affect not only the cortex but also the related short association pathways and the underlying long association bundles as well.

The supramarginal gyrus can first be recognized at about 24 weeks (fig. 7). It is marked off superiorly by the intraparietal sulcus. The angular gryus cannot be identified at this time. By about 28 weeks (fig. 10) both the angular and the supramarginal gyri are present although they are not easily distinguishable. These gyri rapidly become prominent. The angular gyrus takes on a lobulated form (F19), which is still present at term (fig 12). There are three lobules. One of these is mostly posterior or inferior and the other two are largely superior to the superior temporal sulcus. By the second year this lobulation has disappeared.

\section{Association areas}

Parietal association area. The general association area of the parietal lobe is located in the superior parietal lobule and in the superior part of the inferior parietal lobule. From approximately 28 weeks until term the parietal lobe is composed predominantly of the postcentral gyrus and the supramarginal and angular gyri; the superior part of the inferior 
parietal lobule is absent and the superior parietal lobule is small and poorly defined. At the point where the parietooccipital fissure reaches the upper border of the brain, there is a pronounced depression (figs. 8 and 12). With the postnatal enlargement of the parietal association areas, these changes occur: (1) the supramarginal and angular gyri lie farther from the upper border of the hemisphere but retain their relation to the superior temporal and lateral fissures, (2) the parieto-occipital depression disappears, and (3) the parieto-occipital fissure cuts the upper border of the hemisphere at a point considerably more caudal than before birth.

Frontal association area. The Rolandic angle was measured as an indication of the development of the frontal association area. However, no significant variation was found. Such a lack of change is interpreted as indicating a synchronous development of the parieto-occipital and the frontal association areas.

Occipito-temporal association area. Sample measurements of several brains were taken at the angle between the base of the temporal lobe and a line from the occipital pole to the posterior tip of the lateral fissure. It was thought that changes in the angle would reveal any disproportionate growth of either the occipito-temporal cortex within the angle or the parieto-occipital cortex above and outside the angle. No change in the angle was noted, so no detailed measurements were taken.

From the observations made of the association arcas, it may be concluded that these various regions develop concurrently. It should be noted that at term they are not much better developed than in much younger fetuses, although at two years the association areas resemble those of the adult.

PHYLOGENETIC DEVELOPMENT OF CERTAIN NEOPALIIAL REGIONS

\section{Triangular gyrus}

Study of specimens of primate brains in the Laboratory of Comparative Neurology at the University of Michigan and 
of those illustrated by Retzius ('06) has shown that the phylogenetic development of the inferior frontal gyrus in monkeys and apes resembles in some respects the ontogenetic development of the same area in man. It was noted that, in subhuman primates, the fronto-orbital sulcus is located anterior to the precentral sulcus, in a position corresponding to the original single anterior ramus of the human lateral fissure. This sulcus, located anterior to the temporal lobe, is not a true branch of the lateral fissure. It is, however, related to the lateral fissure in that (like the developing anterior ascending ramus of man) its ventral end is continuous with the anterior fissure bounding the insula (Elliot Smith and others quoted by Ariëns Kappers, Huber and Crosby, '36). In higher apes the fronto-orbital sulcus, like the anterior ascending ramus of man, is frequently found to bifurcate (fig. 18). Bolk ('10) reported this condition in the gorilla. The inferior frontal sulcus maintains the same relationship to the fronto-orbital sulcus in monkeys and apes that it does to the anterior ascending ramus in man (figs. 16, 17, and 18). Therefore, according to the criteria used in identifying the anterior rami in the human fetal brain (see section on the ontogenetic development of the triangular gyrus), the frontoorbital sulcus of subhuman primates is homologous with the anterior ascending ramus of the lateral fissure of man.

Bolk ('10) was of the opinion that the fronto-orbital sulcus itself was not homologous with either the anterior ascending or the anterior horizontal ramus, but that the branches of its bifurcated tip were homologous with the two anterior rami of the lateral fissure. His views, then, for the gorilla correspond to those of Cunningham (1892) concerning the ontogenetic development of these rami. Elliot Smith believed the anterior horizontal ramus developed as a lengthening of ramus opercularis and that the anterior ascending ramus was a new structure, produced through the growth of the frontal operculum (Ariëns Kappers, Huber and Crosby, '36).

In Cebus, there is no fronto-orbital sulcus and no triangular gyrus. It is as though the ventrolateral part of the frontal lobe 
had been dissected away at a time when the fronto-orbital sulcus (anterior ascending ramus) was still in a horizontal position, leaving only the upper lip of the sulcus. In the macaque and in Cercopithecus the fronto-orbital sulcus is present (fig. 16). In these forms this sulcus slants upward and forward. This condition is due not to precocity in the development of the surrounding structures, but rather to a lack of development of the frontal association area - especially of the cortex which, in man, lies above the anterior ascending ramus. In the cortex anterior to and below the fronto-orbital suleus is a rudimentary triangular gyrus. In these monkeys and in the ape, the cortex buried in the lateral fissure does not extend far enough forward to play a part in determining the position of the triangular gyrus and its bounding ramus (or rami) as it does in man. In these primates, the triangular gyrus is not so far removed from insular cortex as first seems apparent. The cortex which, in subhuman primates, forms a part of the lateral surface as far anteriorly as the fronto-orbital sulcus, and which is opercularized in man, may be regarded as unopercularized insula (Ariëns Kappers, Huber and Crosby, '36). In the baboon, there is still no anterior horizontal ramus. However, in the mandril (Papio porcarius, illustrated by Retzius, '06) a branch from the orbital sulci approaches the triangular gyrus. This branch may be regarded as a forerunner of the anterior horizontal ramus. Among the apes a greater development of this area is evident. In the orangoutan (Simia satyrus, fig. 17) an anterior horizontal ramus is present. This sulcus, a branch from the orbital sulci, lies on the ventral surface of the brain evidently because of a lack of development of the orbital operculum. In the chimpanzee (Troglodytes niger) the triangular gyrus is well developed (fig. 18) and can be seen easily although the anterior horizontal ramus is still not visible on the lateral surface. In figure 18 the fronto-orbital sulcus has bifurcated and the inferior frontal sulcus arches over it as in the human brain. These observations suggest that the triangular gyrus and its bounding 
rami develop in much the same way phylogenetically as ontogenetically, the fronto-orbital sulcus - or anterior ascending ramus - preceding the anterior horizontal ramus. Such differences as occur between monkeys and apes on the one hand and man on the other are due primarily to the increase in the human frontal association areas.

\section{DESCRIPTION OF 'THE FIBER CONNECTIONS}

In the functioning of the cortex for speech, as in its other activities, the relations of outstanding significance are its fiber connections to and from other cortical and basal areas. In the following pages some of these intercommunicating systems will be reported. This is not a complete account of these connections, many more series cut in a variety of planes and stained by various techniques, supplemented by experimental and clinical material and oscillograph records, will be necessary before enough information has been gathered to make even a reasonably complete story. This paper marks the beginning of what we hope to be a continuing project. It presents some facts necessary as ground work for ablation and stimulation experiments and analyses of complex Golgi and silver material.

The occipital lobe in the monkey has been shown by Poliak ('32) to be concerned with visual functions. Here the retinal quadrants are projected according to a pattern with the superior quadrants (inferior visual fields) projected to the upper half and the inferior retinal quadrants to the lower half of the area. From the upper part of the occipital cortex, beginning with the upper lip of the calcarine fissure, a bundle of fibers passes along the superficial border of the white matter in the superior half of the occipital lobe (where impulses from the inferior visual fields are projected) to reach area 18. From area 18 fascicles (see A, fig. 19) pass to that part of area 19 which is rostral to the lower half of area 17 and 18, that is the more ventral portion of area 19. The stimulation experiments of Crosby and Henderson ('48) indicate 
that this area is concerned with conjugate eye movement downward, and downward and to the opposite side.

Crosby and Henderson ('48) have also shown that from the under lip of the calcarine fissure fascicles pass to adjoining portions of area 18 . From area 18, fibers accumulate along the outer border of the white matter of the hemisphere. They are joined gradually as they pass forward by fascicles from the remainder of area 18 on the inferior surface of the occipital lobe until they constitute a fairly large bundle. This bundle turns dorsorostralward, still following the superficial border of the white matter, and then frays out in the most caudal and dorsal part of area 19. Crosby and Henderson ('48) have found that this part of area 19 on stimulation gives upward movement of the eyes.

Where the bundles from the inferior occipital region and those from the superior occipital region approach each other - and arising apparently from the intermediate regions - are fascicles which distribute to area 19 between those from the superior and the inferior occipital fields (see $\mathrm{B}$ and $\mathrm{C}$, fig. 20). The region reached by this intermediate bundle, on stimulation gives conjugate deviation of the eves toward the opposite side (Crosby and Henderson, '48).

The auditory area in the monkey is situated on the upper part of the exposed surface of the superior temporal gyrus, and on its opercular portion (fig's. 23 and 24). It is not then so completely buried on the opercular face of this gyrus as it is in man, in which case, according to Poliak ('32), "only a few fibers reach the convexity of the superior temporal convolution on the free surface of the temporal lobe." In the monkey, as in other mammals, projection fiber's from the medial geniculate nucleus of the diencephalon pass sublenticularly to the auditory area. Accompanying this bundle are fascicles, apparently of cortico-geniculate and corticotectal character, which pass to the medial geniculate nucleus and the superior colliculus. There are also bundles, presumably of cortical origin, which continue caudalward behind 
the medial geniculate nucleus to the capsule, at least, of the inferior colliculus (Crosby and Henderson, '48).

From auditory cortex association fibers pass to the caudal part of the middle temporal gyrus which is below the region of distribution of the fibers from the upper occipital lobe and near the juncture of areas 19, 20, 21 and 22 (see G, fig. 23). A second interconnection of the auditory cortex with the middle temporal gyrus is provided by a two-neuron chain which undergoes synapse in the superior temporal gyrus, above the deep part ( $X$, fig. 23) of the superior temporal sulcus and below the auditory projection area. There are also fibers which connect the auditory area and the middle temporal gyrus by-passing this region of synapse in their course downward and medially (see H, fig. 23). From the middle temporal gyrus (lower part of areas 19 and 21), and from the underlying inferior temporal gyrus fascicles pass out of the cerebral hemisphere to lower centers. These bundles carry three general types of fibers, cortico-pontine, corticopulvinar (Walker, '38), and the internal cortico-tectal system of Huber and Crosby (Huber and Crosby in Huber et al., ' 43 , for various mammals; Crosby, ' 46 , for the monkey; also Mettler, '32, for the cat). The differential origin of the three systems has not been satisfactorily established but the presence of these association fibers from the auditory cortex suggests that the external cortico-tectal tract is part of a discharge path from auditory cortex to centers of the midbrain where it may make efferent connections.

Short fibers relate the auditory area with the association areas adjoining it. Superiorly the fibers of this bundle pass to the inferior parietal lobule both along the lateral fissure and within the fissure (see G, fig. 23), and to the cortex of the superior lip of the lateral fissure deep to the pre- and postcentral gyri. There are fascicles from these areas into the lower part of the corresponding motor or sensory areas. Since the inferior part of the cental sulcus is directed downward and somewhat posteriorly, more of these fibers are associated with the motor than with the sensory area. In 
the two series studied, many of these bundles passing from the region above the lateral fissure to that below it, do so without synapse in the insula on the right side. On the left side, however, in the region where the fibers join the cortex deep to the motor area, the converse is true (see $\mathrm{E}$ and $\mathrm{F}$, fig. 22). It is evident then that the auditory area is connected with that portion of the motor area which controls the muscles of the larynx, tongue, and lips - that is, the musculature involved in vocalization and articulation. To a lesser extent the auditory area is related to the corresponding part of the sensory area. This connection is by way of a $3-$ or 4-neuron chain from the auditory projection area to adjoining association cortex and from there to the cortex adjacent to the motor or sensory area. The impulses may pass from the auditory association area to the insula and from the insula to the cortex bordering on the motor or sensory areas. There are also direct bundles from the auditory projection area to the sensory area.

The superior longitudinal and the inferior fronto-occipital fasciculi interconnect various cortical areas of the hemisphere from its frontal to its occipital pole. The superior longitudinal fasciculus lies above and medial (fig. 21), and the inferior fronto-occipital fasciculus lies below and medial to the claustrum (fig. 23). As these bundles go forward their fibers fan out and intermingle with the rest of the white matter. Such is their position that deep lesions of the triangular gyrus must almost necessarily involve them. The superior longitudinal fasciculus contains fibers which interconnect the insula, upper and anterior part of the claustrum (see D, fig. 21), and the frontal cortex, including area 4 and probably the triangular gyrus, with the occipital and temporal cortices. These anterior areas are also interconnected with one another through this fasciculus but the bundle is largest in the region of area 4 so it is logical to assume that there are many interconnections between these anterior areas and those lying posterior to the central sulcus. The inferior fronto-occipital fasciculus carries fibers which 
interconnect frontal and occipito-temporal cortex. The indications are that the part of the occipital cortex on which are projected impulses from the upper retinal quadrants is related to the frontal cortex through the superior longitudinal fasciculus and the part which receives impulses from the lower retinal quadrants through the inferior fronto-occipital fasciculus.

It is evident then that the triangular gyrus is a nodal point in a series of association systems. Destruction in this area will profoundly affect the richness of associations in regions distant from the site of the lesion and impoverish the general association pattern of the cerebral hemisphere.

\section{DISCUSSION}

The organs used for speech serve a dual function - that of speech and some vegetative process. Similarly the cortical control of speech is brought about through the adaptation of cerebral association fibers rather than through the activity of any cortical areas specially designed for purposes of language. Consequently, if such association pathways are interrupted, there are disturbances in the thinking processes underlying speech. It is therefore possible for a loss of articulate speech to result from lesions in parts of the hemisphere other than Broca's area, particularly on the dominant side, if such lesions interfere seriously with the association pathways. As Nielsen ('47) has pointed out, in order to talk you must have something to say.

The pattern of association pathways has been considered in the section dealing with fiber bundles in the brain of Macaca mulatta. Tracts were found which relate visual projection with visual psychic areas, and auditory projection with auditory psychic and general association areas. These areas are in turn connected with the association regions of the frontal cortex, claustrum and insula, and with the motor area. The triangular gyrus, fibers of which also contribute to this pattern, overlies the bundles which connect the frontal cortex with the other areas just mentioned. Articulate specch 
is a highly coordinated type of motor expression based upon impulses reaching the sensory areas, colored by impulses involving the association areas and then passed over to the motor centers. Lesions of the triangular gyrus destroy the fibers related to that area and may also interrupt the pathways to the frontal cortex, and therefore greatly impoverish the fiber systems upon which speech depends.

Phylogenetically, as ontogenetically, the understanding of speech appears before its motor expression. Orton ('35) has pointed out that many animals (as $\operatorname{dog} \mathrm{s}$ ) learn the meaning of words, although, on the motor side their communication is solely on an emotional basis. Hines ('42) observed that the macaque uses a propositional type of speech as well as the emotional type. Garner ('07), who studied animals in their natural habitat, discussed the differences in speech of a number of monkeys and apes and regarded some as exceedingly talkative. Although no detailed study of this kind was carried on for this paper, observations were made of the speech and behavior of a young macaque and its mother. Much of the sound emitted by the monkeys obviously was no more than noisy screaming but it was evident that in their more quiet moments there was some communication by vocalization between the two.

Before discussing articulation in the monkey some reference to its development in the human should be made. It has been suggested that vowel sounds are based on swallowing movements and that underlying consonant sounds are swallowing, sucking' and chewing movements (Shohara, '32, '35). Swallowing and sucking are established prenatally swallowing by 13 weeks, and sucking by 29 weeks (Hooker, '44). Thus, at birth, the foundation has been laid for all vowel and some consonant elements. Although the order in which sounds develop is not rigidly fixed, vowels tend, with some overlapping, to appear before the consonant sounds (West, Kennedy and Carr, '37). Initial consonants are used in syllables before final consonants, and single consonants precede consonant combinations such as bl, cr, et cetera. It 
should be stressed that the ability to articulate sounds is present before their utilization for speech purposes, just as the vegetative processes on which speech sounds are based precede the ability to articulate those sounds. There is, however, a considerable overlap in the development of these activities. Some of the sounds dependent upon swallowing and sucking movements appear before the child learns to chew. Later, with the maturation of cortical association bundles, the child begins to use words although he may not have mastered all the more difficult sounds or sound combinations.

Detailed studies of the speech sounds of the monkey were made by Paget ('30) and of the chimpanzee by Learned ('25). In our work it was observed that the speech pattern of the baby macaque and its mother was altered not only by a variety of sound elements but also by variation in the pitch and the duration of sound. The sound elements consisted mostly of nasalized vowels and the nasal consonants: 1 (ng), $\mathrm{m}$, and $\mathrm{n}$. These consonants, among the first acquired in man, are based on swallowing $(\mathrm{y})$ and swallowing and sucking movements $(m, n)$ (Meader, '40). No use of the soft palate for the production of speech sounds could be detected although Paget ('30) listed "a soft-palatal release"' among the consonant sounds of monkeys, and Learned ('25) included $\mathrm{g}$ and $\mathrm{k}$ among the consonant sounds of the chimpanzee. Single, initial consonants were often used by the baby macaque and its mother although there were no final consonants or consonant combinations. Learned ('25) noted that combinations and final consonants were both employed by the chimpanzee.

It is evident that the sounds used by the monkey are those which appear early in human speech. The nasality of the monkey sounds also indicates a correlation with developing human articulation as many believe that soft-palatal action in articulation is one of the later human acquisitions. The use of only initial, single consonants by the macaque suggests a further correlation with an early stage in the human development of articulation. It is interesting to note that 
the chimpanzee, using final consonants and consonant combinations (Learned, '25), has a greater articulatory range than does the macaque, and that he is more nearly like the human in this respect.

The rudimentary speech of the macaque has, for its anatomic basis, a complex associational pattern in which visual, auditory, and other sensory stumuli come into relationship with one another and discharge toward motor centers. The frontal lobe component of this pattern is small in monkeys. In man, with the great increase in the association areas, especially those of the frontal lobe, there is an increase in the frontal lobe component to the triangular gyrus and additional connections with other associational areas of the hemisphere. Consequently, the anatomical pattern underlying speech activities is greatly enriched in man. This augmentation of interconnections finds functional expression in the much varied and complex human speech.

\section{LITERATURE CITED}

AriËns KapPers, C. U., G. C. Huber AND E. C. Crosby 1936 The comparative anatomy of the nervous system of vertebrates, including man. The Macmillan Company, New York, 2 vols.

BoLk, L. 1910 Beiträge zur Affenanatomie VII Das Gehirn von Gorilla. Zeitschr. f. Morphol. u. Anthropol., 12: 141-242.

Bord, E. 1941 Outline of physical growth and development. Burgess Publishing Company, Minneapolis, Minn. 43 pp.

Broca, P. 1861a Remarque sur le siége de la faculté du langage articulé, suives d'une observation d'aphémie (perte de la parole). Bull. d. I. Soc.

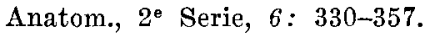

1861b Nouvelle observation d'aphémie produite par une lésion de la moitié postérieure des deuxième et troisième circonvolutions frontales. Bull. d. 1. Soc. Anatom., 2e Serie, 6: 398-407.

Connoliz, C. J. 1940 Development of the cerebral sulei. Am. J. Phys. Anthrop., 26: $113-149$.

Crossr, E. C. 1946 The neuroanatomical patterns involved in eertain eye movements. Henry Russell lecture presented at Univ. of Mich., Ann Arbor, Mich,, May, 1946.

Crosbr, E. C., AND J. W. HENDERson 1948 The mammalian midbrain and isthmus region. Part II. Fiber connections of the superior colliculus. B. Pathways concerned in automatic eye movements. J. Comp. Neur., $88: 53-92$. 
Cunsingmax, J), J. 1891 The development of the gyri and sulci on the surface of the island of Reil of the human brain. J. Anat. and Physiol., 25: $338-348$.

1892 Contribution to the surface anatomy of the cerebral hemispheres with a chapter upon eranio-cerebral topography by V. Horsley. Roy. Irish Acad., Cunningham Memoirs, no. 7 .

Ererstaldier, O. 1887 Zur Anatomie und Morphologie der Insula leilii. Anat. Anz., 2: 739-750.

Garnter, R. L. 1907 Speech and babits of wild animals. The Independent, $63: 138-142$.

Goldstrin, K. 1926 Über Aphasie. Seliweiz. Areh. f. Neurol. u. Psyehiat., 19: $3-38,292-322$.

IIEAD, II. 1915 Hughlings Jackson on aplasia and kindred affections of speech, together with a complete bibliography of his publications on speeeh and a reprint of some of the more important papers. Brain, 38: $1-190$.

1926 Aphasia and kindred disorders of speech. Univ. press, Cambridge, 2 vols.

Hinks, M. 1942 The development and regression of reflexes, postures, and progression in the young macaque. Carnegie Inst. of Washington Publ. 54.1, Contrib. to Embryol., no. 196, pp. 153-209.

Ilooksk, D. 1944 The origin of overt beharior. Univ. lecture presented at Univ. of Mich., April, 1943, Univ. of Mich. Press, Ann Arbor, Mich.

Huber, G. C., E. C. Crosby, R. T. Woodbltrey, L. A. Glldilan, J. O. Brown AND B. TAMthaI 1943 The mammalian midbrain and istlumus regions. T. The nuclear pattern. J. Comp. Neur., r $8: 133-534$.

JoRDAN, H. E., AND J. E. KindRED 1932 A textbook of embryology. D. Appleton and Company, New York, N. Y.

KodsMa, S. 1926 Über die sogenannten Basalganglien, Morphogenetisehe und pathologiseh-anatomische Untersuchnuger. Schweizer Areh. Neur. u. Psyels. 18: 179-246.

Kolıann, J. 1898 Lchrbuch der Entwickelungsgeschichte des Mensehen, Fischer, Jena.

1907 Handatlas dex Entwicklung gesehichte des Mensehen, Fischer, Jena.

LEARNED, B. W. 1925 Voice and "language" of young chimpanzees. In Chimpanzee intelligence and its voeal expressions, by R. M. Yerkes and B. W. Tearned. Williams and Wilkins Company, Baltimore, MA.

Mats, F. P. 1903 On the transitory or artifical fissures of the human cerebrum. Am. J. Anat., 2 : 333-340.

Marte, P. 1906a Revision de la question de l'aplassie: La troisième circonvolution frontal gauche ne joue aucun rôle spécial dans la fonction du langage. Semaine méd., 26: 241-247.

$1906 \mathrm{~b}$ Que faut-il penser des aphasies sous-corticales (aphasies pures)? Semaine méd., $26: 493-500$.

$1906 \mathrm{c}$ L'aphasie de 1861 à 1866 ; essai de critique historique sur la genèse de la doctrine de Broca. Semaine méd., 26: 565-571. 
Marie, P., And C. FoIx 1917 lues aplasies de guerre. Rev. Neur. 81: 53-87.

Mrader, M. H. 1940 The effect of disturbances in the developmental processes upon emergent specificity of function. J. Speech Disorders, 5: 211219.

Metrler, F. A, 1932 Connections of the auditory cortex in the cat. J. Comp. Neur., 55: 227-243.

Niflsen, J. M. 1947 Agnosia, apraxia, aphasia; their value in cerebral localization. P. B. Hoeber, Ine., New York, London, 292 pp.

OrToN, S. T. 1935 The development of speech understanding in relation to intelligence. Child Reseatch Clinic Series, 1 : 5-12.

PAGeT, R. 1930 Human spech. Hareourt, Brace and Company, New York, N. $Y$.

Poliak, S. 1932 The main afferent fiber systems of the cerebral cortex in primates. Univ. of Calif. Press, Berkeley, Calif. $370 \mathrm{pp.}$

Retzius, G. 1896 Das Menschenhirn. Studien in der makroskopischen Morphologie. P. A. Norstedt u. Soner, Stockholm.

1906 Das Affenhirn in bildlicher Darstellung. P. A. Norstedt $u$. Soner, Stockholm.

ShoharA, H. H. 1932 A contribution to the genesis of the articulatory movements of speech with special reference to the processes of sucking, chewing, and swallowing. Dissertation, Dept. of Speech, Univ. of Mich.

1935 The genesis of the articulatory movements of speech. Quart. T. Speech, 21: $343-348$.

Straeter, G. L. 1912 The development of the nervous system, In Manual of human embryology, by $\mathbf{F}$. Keibel and $\mathbf{F}$. P. Mall, vol. 2, clap. 14, pp. 1-116, J. B. Lippincott Company, Philadelphia.

Symington, J. 1901 On the temporary fissures of the human cerebral hemis. pheres, with observations on the development of the hippocampal. fissure and hippocampal formation. Brit. Assoc. Adv. Sci., Glasgow.

WALKER, A. E. 1938 The primate thalamus. Univ. of Chicago Press. Chicago. $321 \mathrm{pp}$.

Wrisenberg, T. H., AND K. E. MCBride 1935 Aplasia, a elinical an logical study. Oxford Univ. Press, Mumphrey Milford, London.

WerNICKE, C. 1874 Der aphasische Symptomeneomplex. Breslau.

West, R., L. KenNedy and A. CARR 1937 The rehabilitation of speech. Harper and Bros., New York, N. Y., 475 pp.

Woolssey, C. N., AND E. M. WAI, 1942 Topical projection of nerve fibers from local regions of the cochlea to the cerebral cortex of the eat. Bull. Johns Hopkins Hosp., 71: 315-344. 


\section{ABBREVIATIONS}

A, fibers conmecting upper part area 18 and rostral part area 19

ang.g., angular gyrus

a.as.r., anterior aseending ramus of lateral fissure

a.b.r.I., anterior bounding ramus of insula

a.ca.f., anterior limb of calcarine fissure

a.H.ev., anterior Hechl's convolution a.h.r., anterior horizontal ramus of lateral fissure

au.ar., auditory area

B, fibers connecting intermediate portions of area 18 and area 19

$\mathrm{C}$, fibers connecting intermediate portions of area 18 and area 19

ca.f., calcarine fissure

ca.n., calcarine notch

e.s., central sulcus (of Rolando)

c.s.I., central sulcus of insula

cir.s., circular suleus

cl., claustrum

$\mathrm{D}$, fibers from superior longitudinal fascieulus to elaustrum

$\mathrm{E}$, fibers connecting frontal operculum and insula

e.cap., external capsule

F, fibers connecting superior temporal gyrus and insula

fr.or.s., fronto-orbital suleus

fr.pa.op., fronto-parietal operculum

$G$, fibers connecting superior temporal gyrus and middle temporal gyrus
H.ev., Heschl's convolutions

i.fr.o.fas., inferior fronto-occipital fasciculus

i.fr.s., inferior frontal sulcus

i.pa.Iob., inferior parietal Iobule

I., insula

l.f., lateral fissure

1.v., lateral ventricle

m.t.g., middle temporal gyrus

m.t.s., middle temporal sulcus

or.s., orbital suleus

pa.o.f., parieto-oceipital fissure

pa.o.d., parieto-occipital depression

po.s., postcentral sulcus

p.ca.f., posterior limb of calcarine fissure

p.as.r., posterior ascending ramus of lateral fissure

pr.s., precentral sulcus

pm.H.cv., primordia of Heschl's convolutions

pu., putamen

su.lo.fas., superior longitudinal fasciculus

su.t.g., superior temporal gyrus

su.t.s., superior temporal suleus

sm.g., supramarginal gyrus

t.co.pon., temporo-cortico-pontine tract

trg.g., triangular gyrus

tru.s., transitory sulei

$X$, region of synapse for fibers connecting auditory area and middle temporal gyrus 

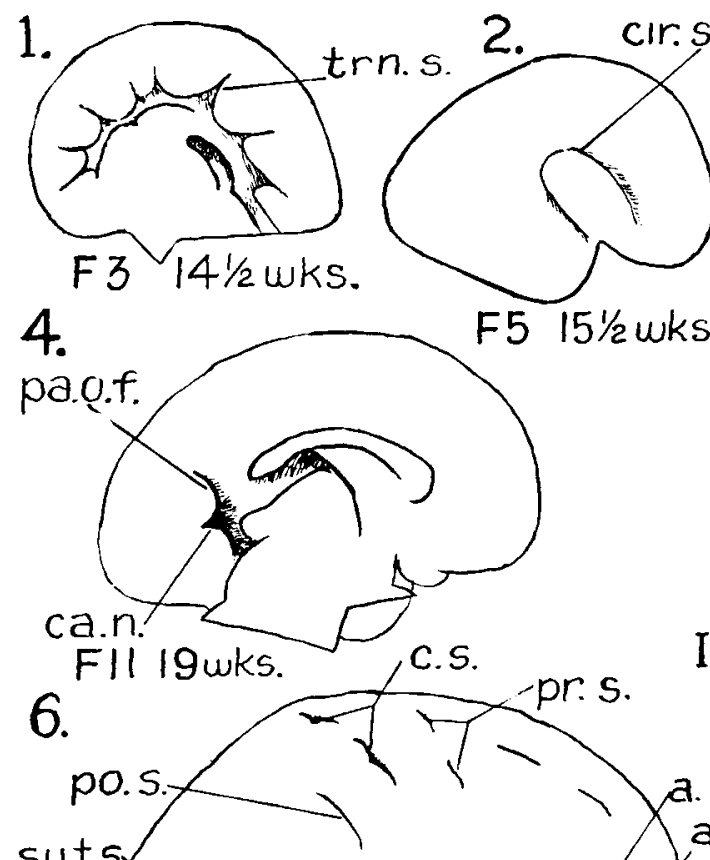

a. as.r.

abri. Fll $19 w k s$.
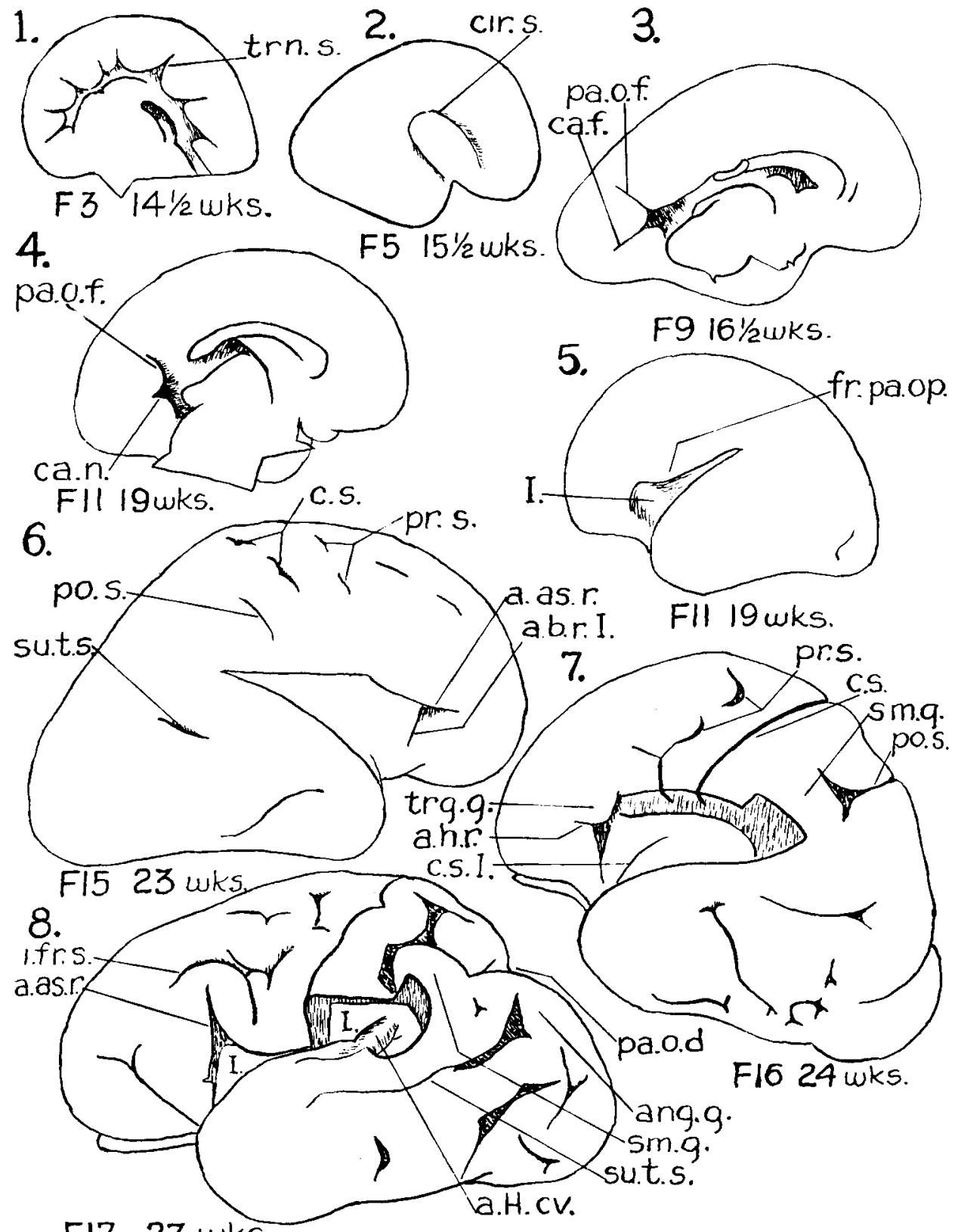

FI7 27 wks.

1 to $\dot{12}$ Drawings made from photographs and seale drawings of the material. $(\times 1)$ 


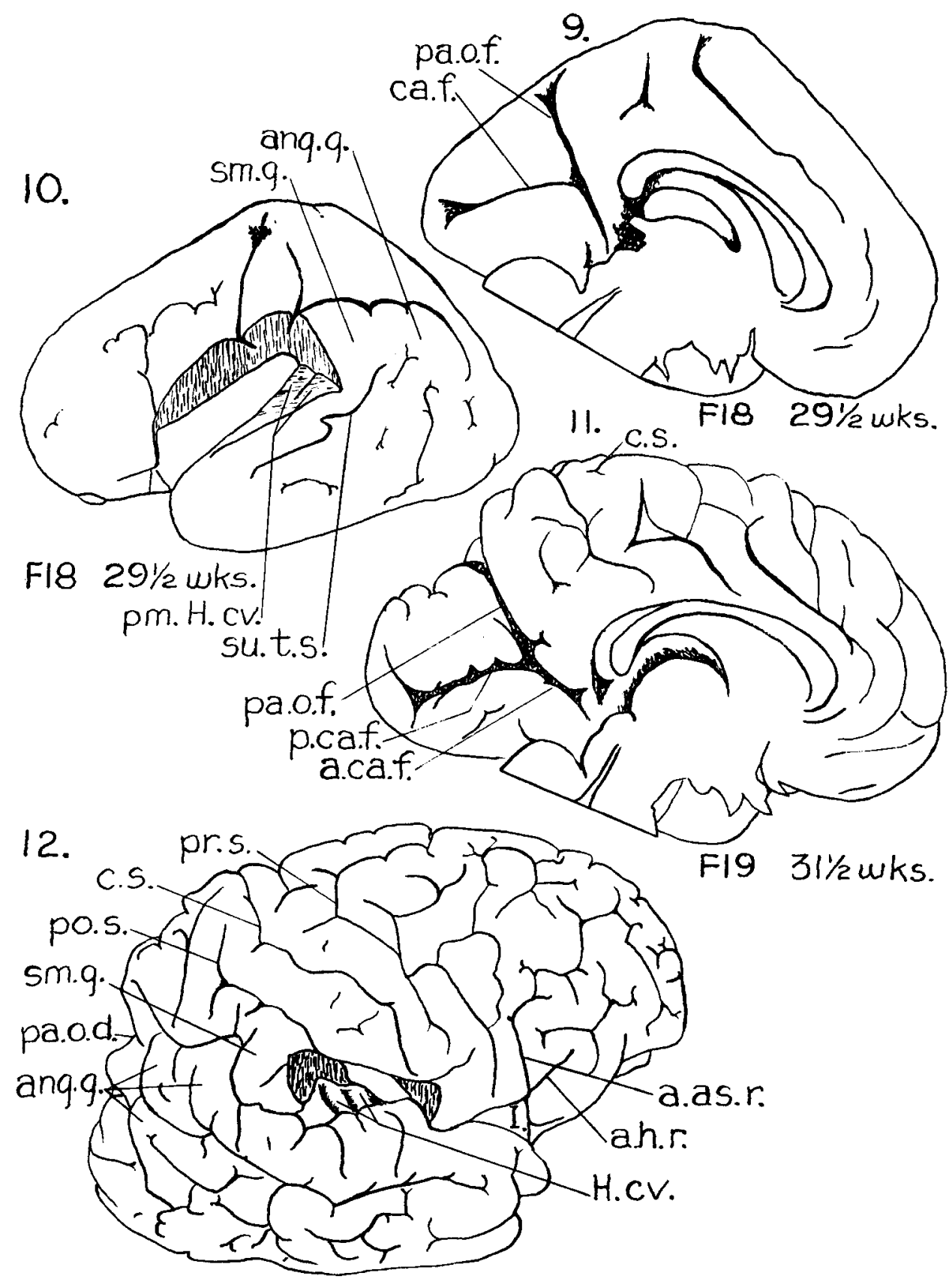

F20 40wks. 

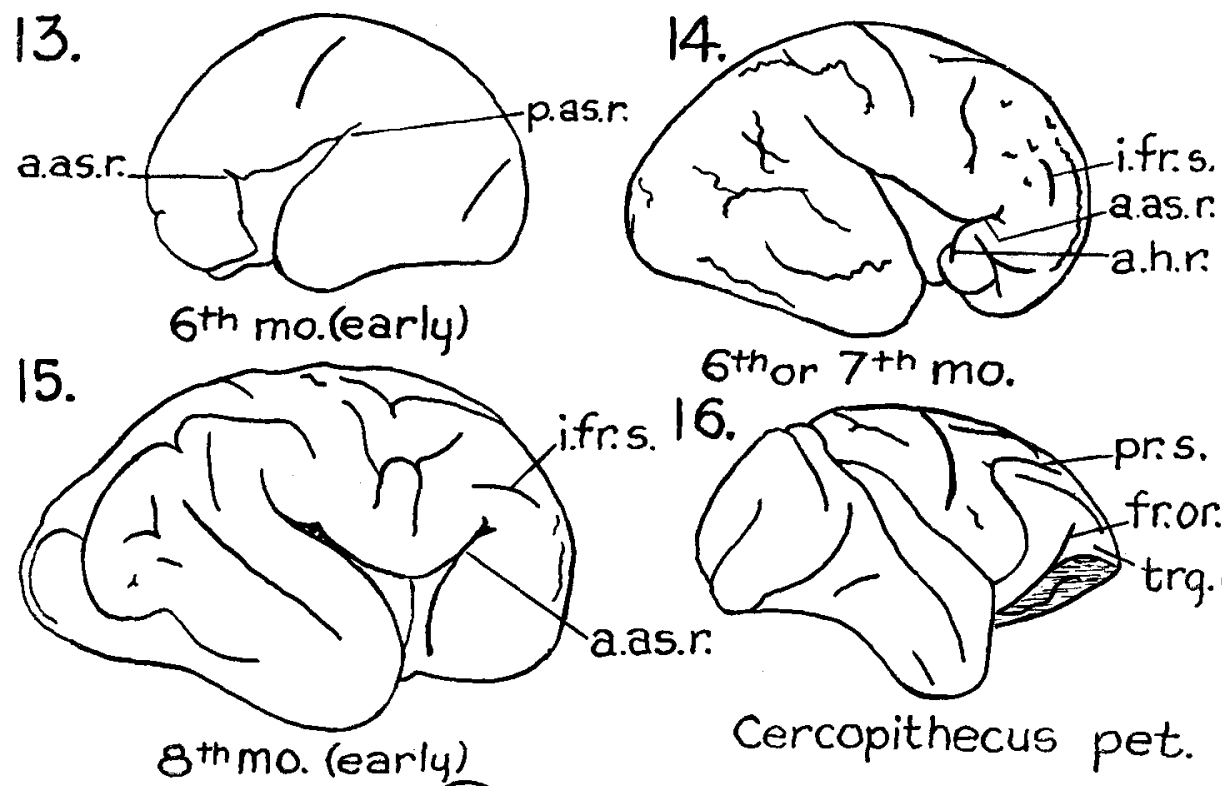

$6^{\text {th }}$ or $7^{\text {th }}$ mo.

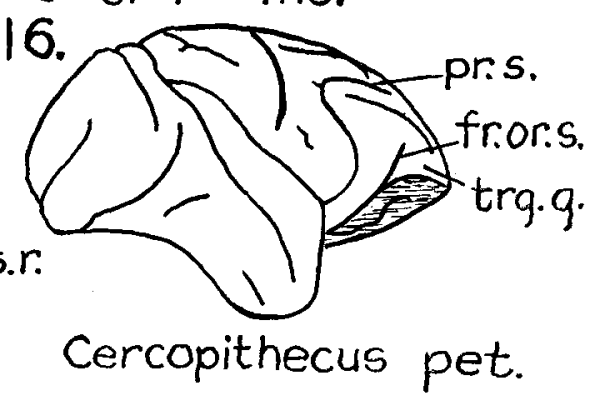

17.
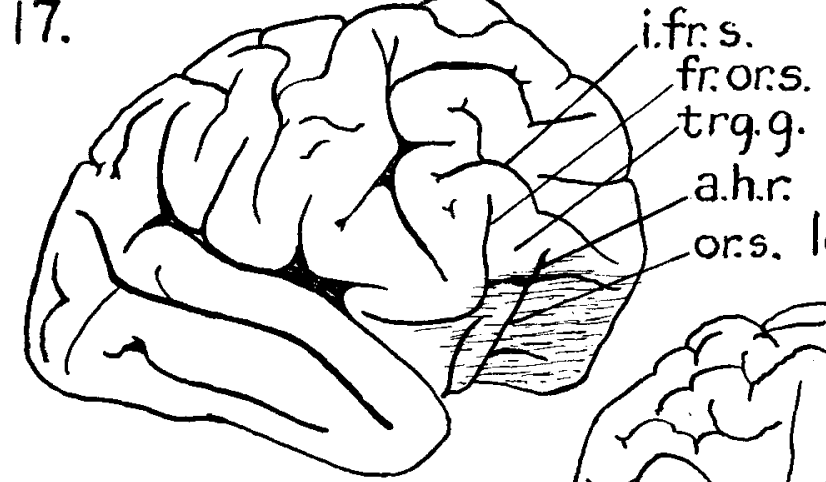

simia sat.

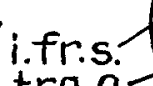

trg. 9 .

fror.s.

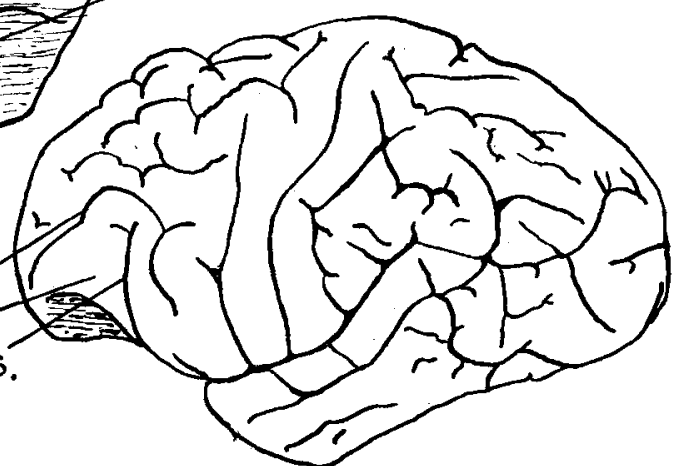

Troglodytes nig.

13 to 15 Drawings adapted from ilhustrations in "Das Menschenhirn", by G. Retzius $(1896) \cdot(\times 2 / 3)$

16 to 18 lorawings adapted from illustrations in "Das Affenhirn" by G. Retzius ('06). $(\times 2 / 3)$ 

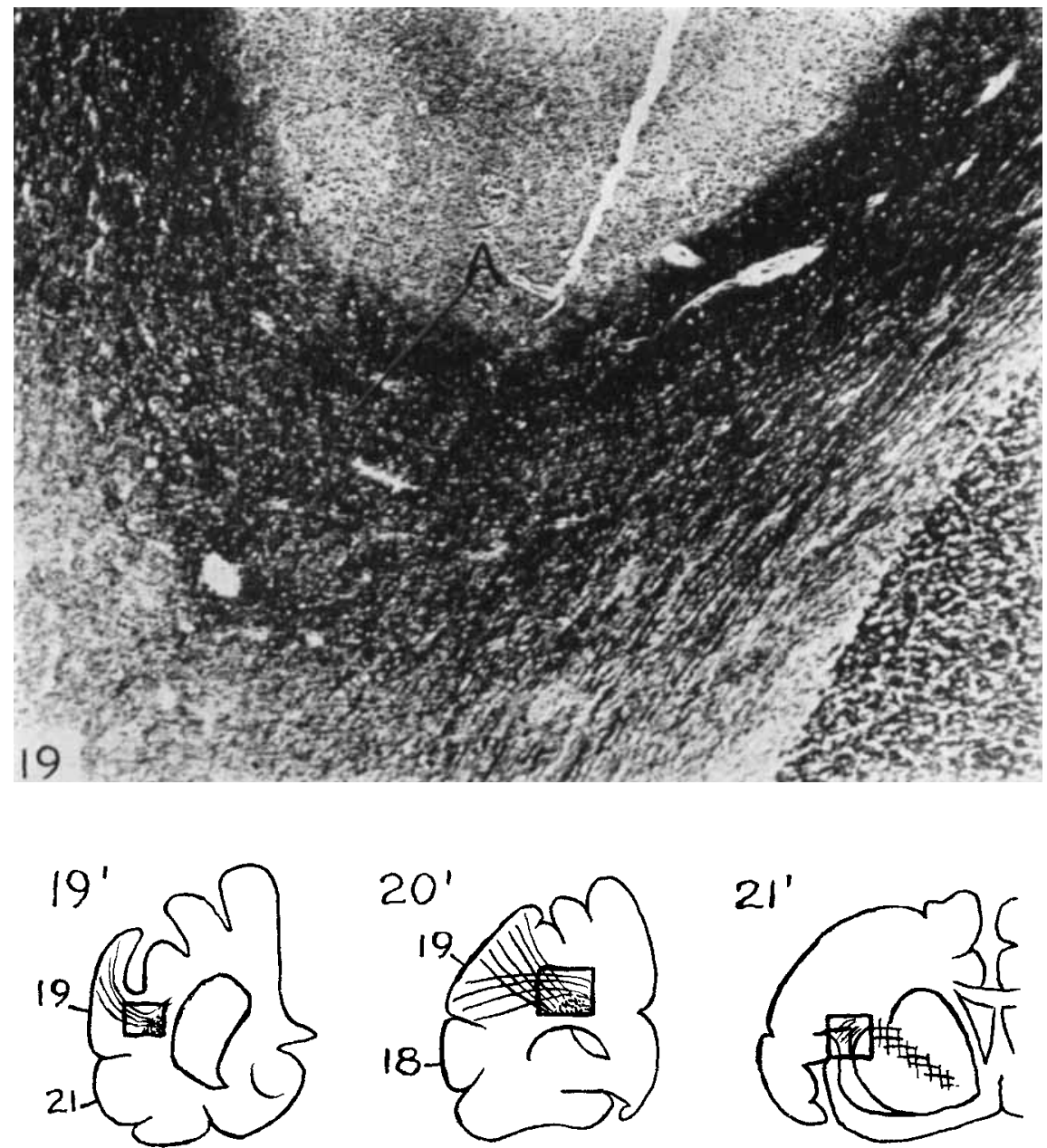

19 to 23 Photomicrographs of selected portions of transverse sections through brain of Macaca mulatta. Weil technique.

19 to 21 Fascicles labeled include connections between rpper part area 18 and area 19 (A), intermediate portions of area 18 and area 19 ( $B$ and $C$ ), and fibers from superior longitudinal fasciculus passing to the claustrum (D). Key drawings $19^{\prime} 20^{\prime}$ and $21^{\prime}$ are included for orientation. $(\times 42)$

29 and 23 Fascicles labeled include connections between frontal operculum and insula (E), insula and superior temporal gyrus (F), parietal operculum and superior temporal gyrus (G) and middle and superior temporal gyrus $(H),(\times 10)$ 

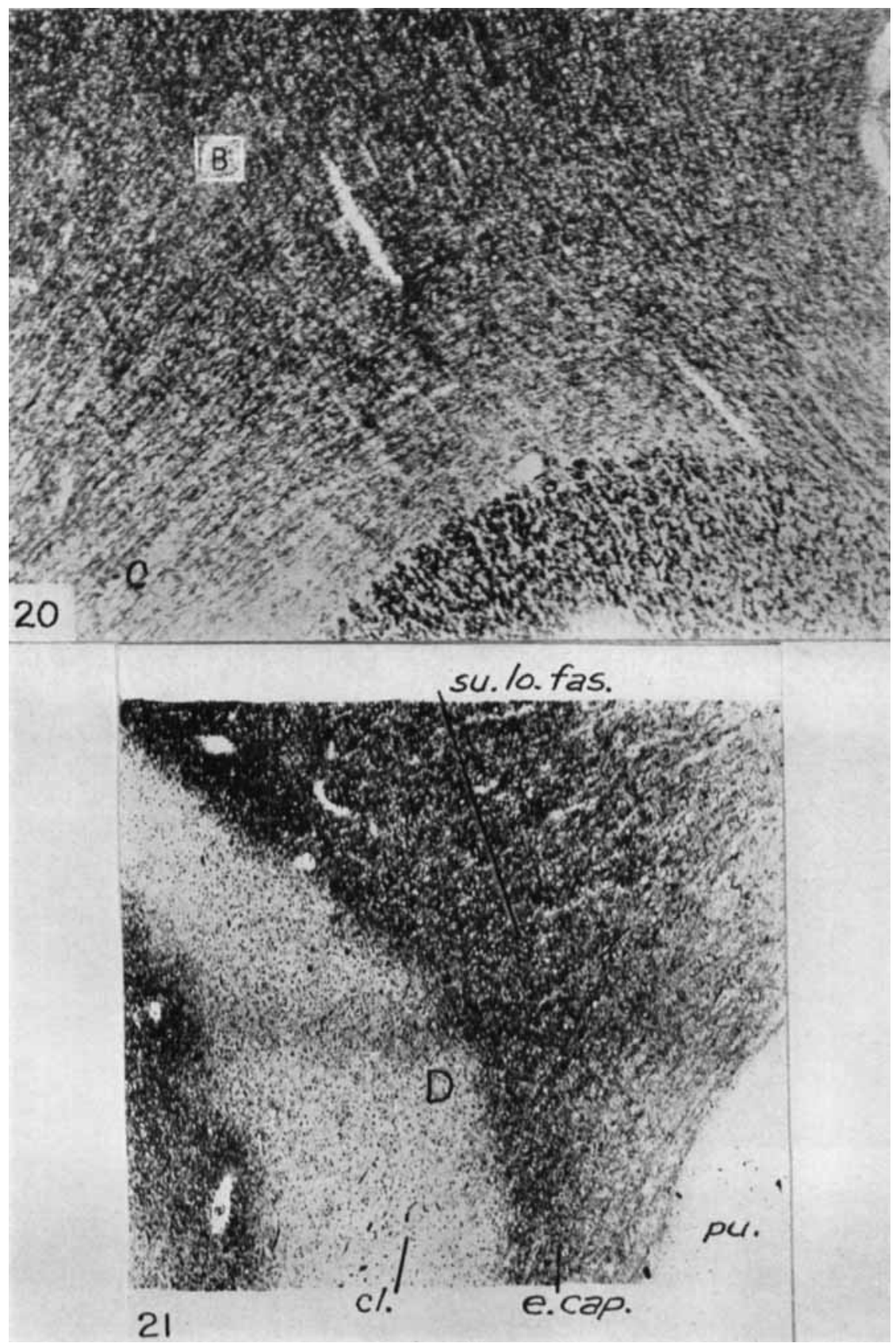


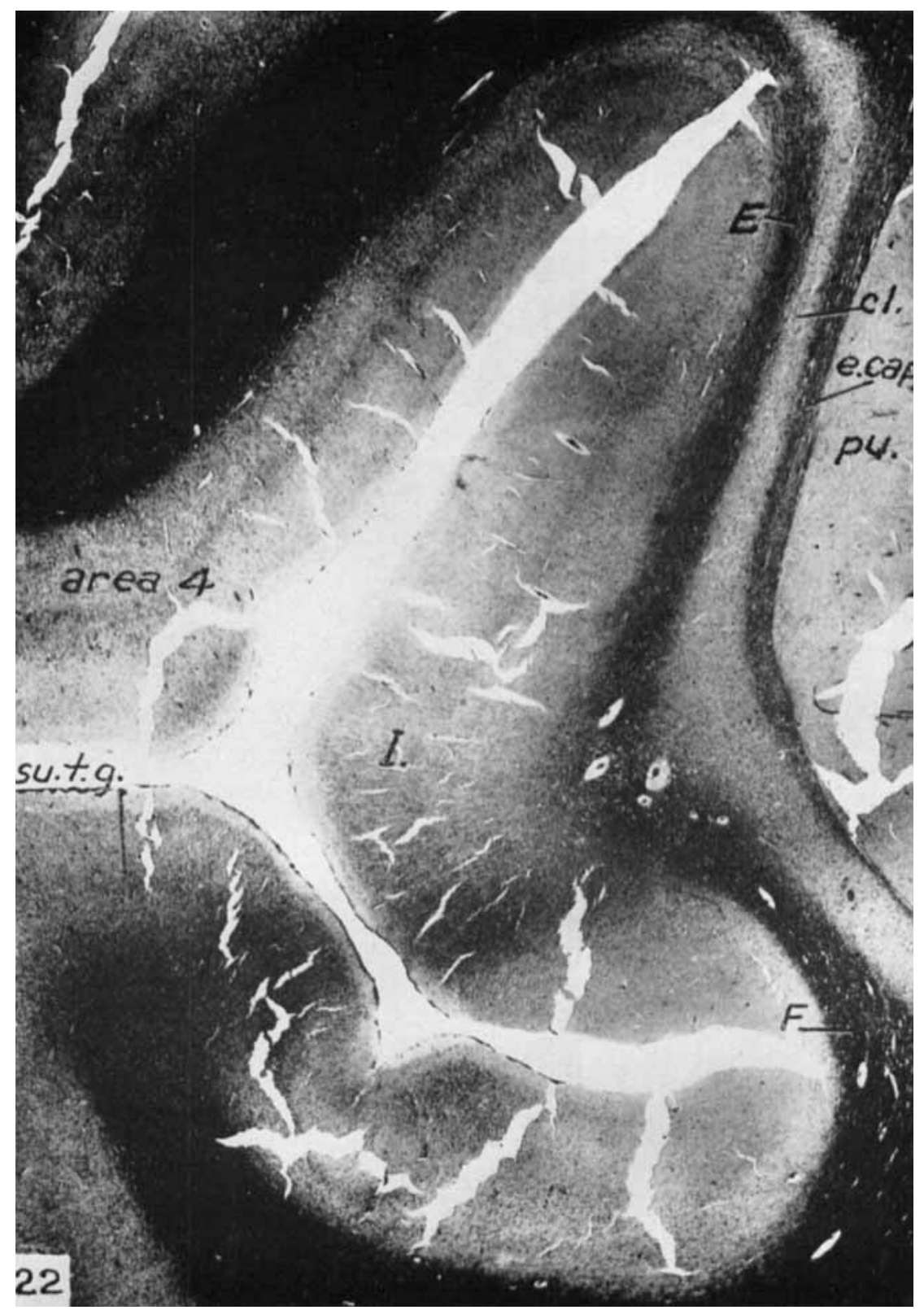




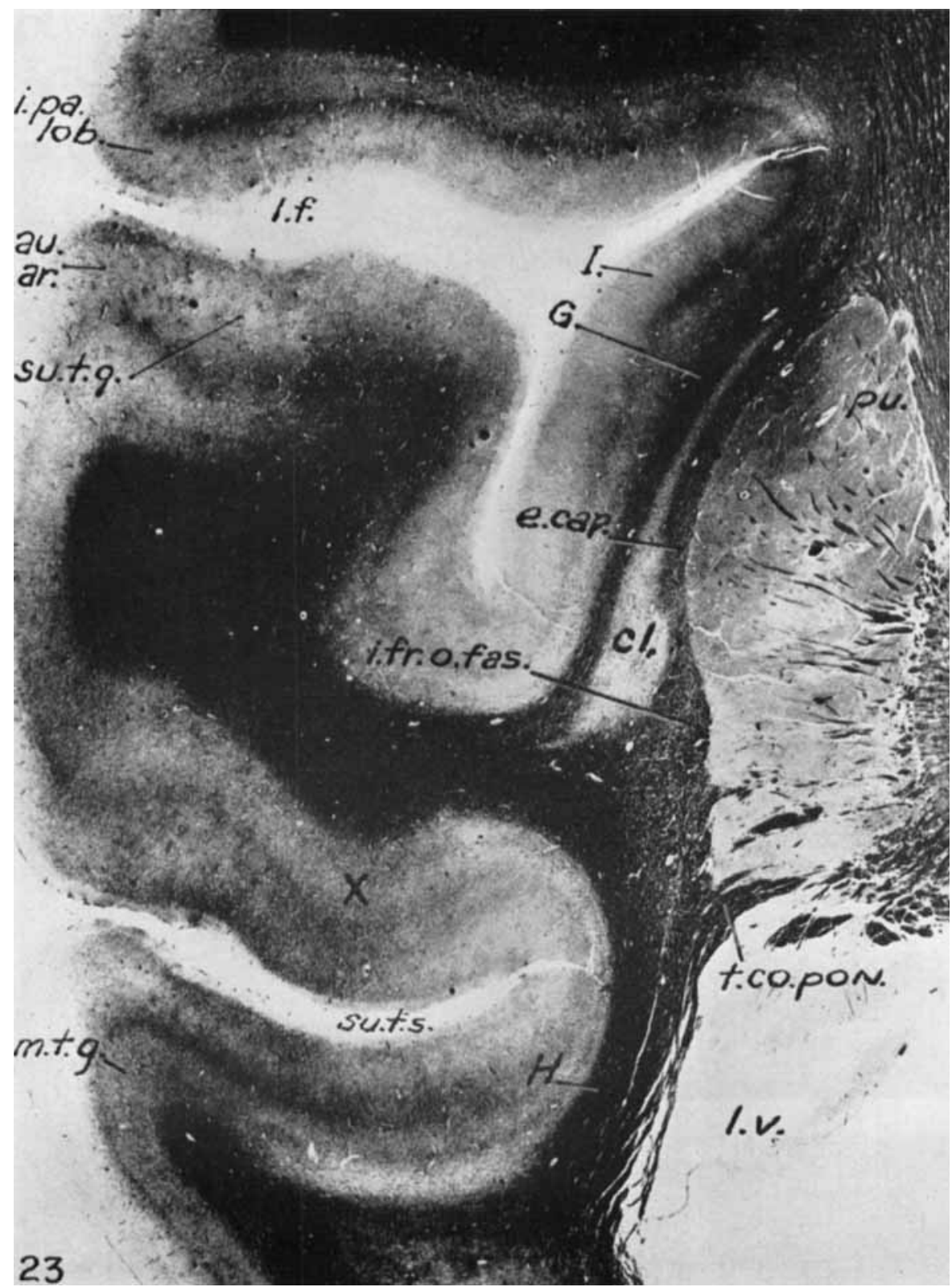



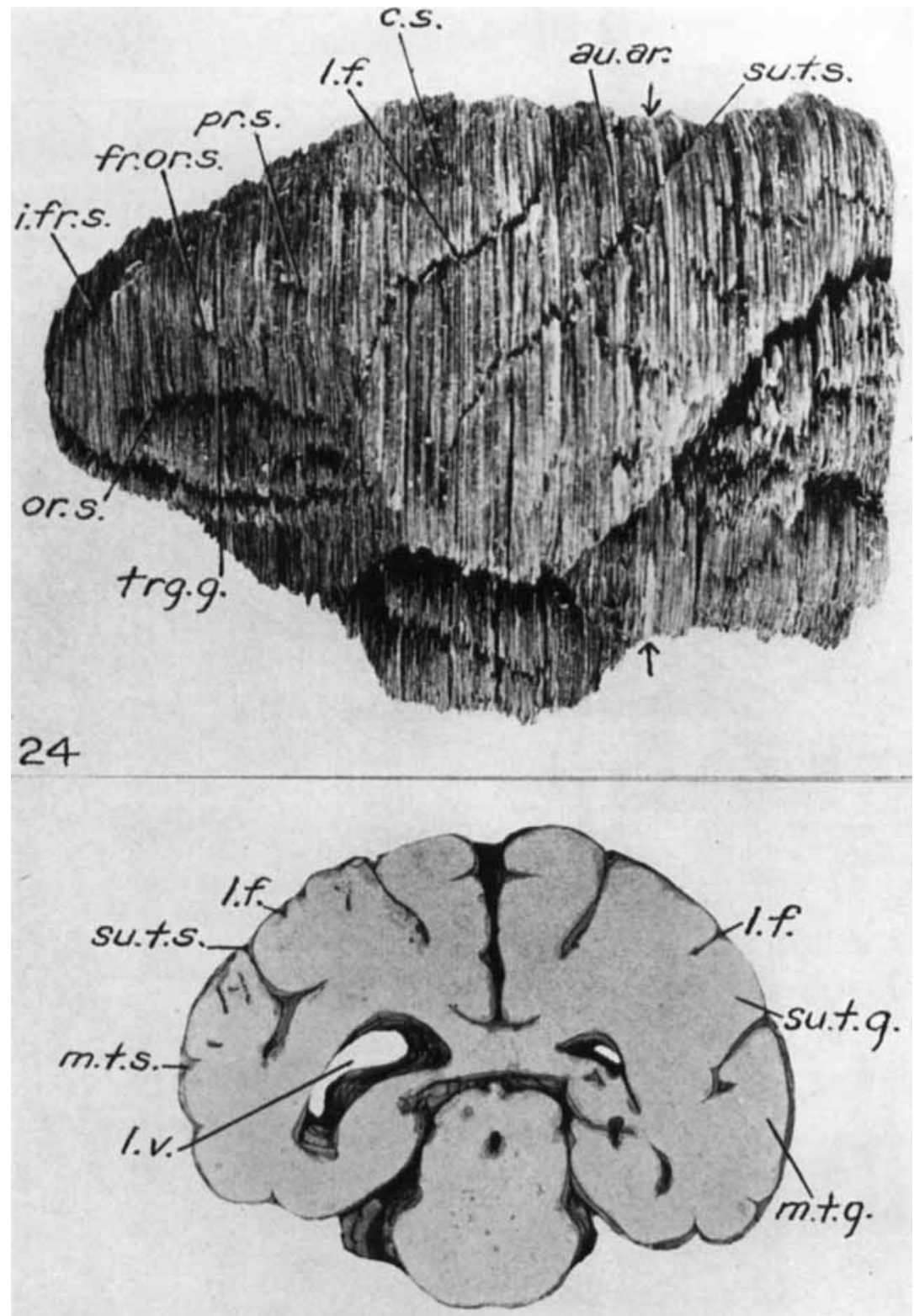

25

24 Latero-ventral view of left side of reconstruction of brain of macaque, showing some of the cortical areas described in text. $(\times 1 / 3)$

25 Rostral view of typical block (cross section) of reconstruction at level indictated by arrows on figure $24 .(\times 1 / 3)$ 